\title{
Association of Chronic Khat Chewing with Blood Pressure and Predictors of Hypertension Among Adults in Gurage Zone, Southern Ethiopia: A Comparative Study
}

This article was published in the following Dove Press journal:

Integrated Blood Pressure Control

\section{Teshome Gensa Geta' \\ Gashaw Garedew \\ Woldeamanuel (ID) \\ Bereket Zeleke Hailemariam (D) \\ Diribsa Tsegaye Bedada ${ }^{2}$}

'Department of Biomedical Sciences, School of Medicine, College of Medicine and Health Sciences, Wolkite University, Wolkite, Ethiopia; ${ }^{2}$ Department of Statistics, College of Natural and Computational Sciences, Wolkite University, Wolkite, Ethiopia
Correspondence: Teshome Gensa Geta Department of Biomedical Sciences, School of Medicine, College of Medicine and Health Sciences, Wolkite University, P.O. Box 07, Wolkite, Ethiopia Tel +25 I 91068650 I

Email teshgen2006@gmail.com
Purpose: The leaves of the Khat plant contain amphetamine-like compounds which are implicated in the development of hypertension. The increase in blood pressure coincides with the plasma cathinone level. Other factors associated with hypertension are being overweight, obesity, cigarette smoking, alcohol use, physical inactivity, unhealthy diet, and stress. Thus, this study assessed the association of chronic khat chewing with hypertension and other factors associated with hypertension.

Patients and Methods: Acommunity based comparative cross-sectional study was undertaken from October 5, 2018 to February 15, 2019 in Gurage zone, southern Ethiopia. A total of 1200 adults (600 chewers and 600 non-chewers) aged $18-65$ years were selected using a convenience sampling method. The data was collected by an interviewer-administered questionnaire plus physical measurements and were carried out at a fixed time of the day in the morning (7: $00 \mathrm{am}-10: 00 \mathrm{am})$. Linear regression and binary logistic regression analysis were performed to identify the determinant factors of blood pressure. The test of statistically significant association was declared by using $95 \% \mathrm{CI}$ and $\mathrm{p}$-value less than 0.05 .

Results: A total of 1198 adults participated in the study giving a response rate of $99.8 \%$. The mean age of Khat chewers were $34( \pm 11.27)$ and non-chewers were $34.73( \pm 11.48)$ years. The mean values of systolic blood pressure and diastolic blood pressure were higher in chewers than in non-chewers $(p<0.001)$. The prevalence of diastolic blood pressure $>80 \mathrm{mmHg}$ was significantly higher among Khat chewers than in non-chewers $(17.4 \%$ versus $8.7 \%, \mathrm{p}<0.001)$. The duration of Khat chewing was significantly associated with systolic blood pressure (Beta coefficient $=0.83, \mathrm{p}<0.001)$ and diastolic blood pressure (Beta coefficient $=0.51, \mathrm{p}<0.001)$. The sex, age, BMI and alcohol were significantly associated with both systolic and diastolic blood pressure.

Conclusion: Chronic Khat chewing, male sex, BMI and alcohol were associated with increased systolic and diastolic blood pressure. To assess the cause and effect relationship between chronic Khat chewing and hypertension further studies with better defined cohorts and basic science studies need to be undertaken.

Keywords: chronic khat chewing, systolic blood pressure, diastolic blood pressure

\section{Introduction}

Khat was first identified by the botanist Forskal in 1762. There is a long history of Khat chewing in the Horn of Africa and the Arabian Peninsula. Khat chewing for social and psychological reasons has been practiced in Ethiopia for many centuries ${ }^{1}$ 
and is known by different names in different countries: Khat in Ethiopia, Qat in Yemen, Mirra in Kenya and Qaad or Jaad in Somalia. ${ }^{2,3}$

The leaves of the Khat plant contain amphetamine like compounds (cathinone and cathine) which increase both blood pressure and heart rate. The increase in blood pressure coincides with the rise of plasma levels of cathinone levels. The increase in blood pressure is caused by the vasoconstrictor activity of cathinone., ${ }^{4,5}$

Hypertension is a major global public health challenge. The estimated total number of people with hypertension in 2000 was 972 million (95\% confidence interval [CI]: 957-987 million) of which 333 million $(95 \%$ CI: 329-336 million) were in economically developed countries and 639 million (95\% CI: 625-654 million) in economically developing countries. ${ }^{6}$

The prevalence of hypertension in Ethiopia was estimated to be $19.6 \%$ ( $23.5 \%$ in the urban population and $14.7 \%$ in rural and urban population). It was also shown that the prevalence of hypertension in males and females was $20.6 \%$ and $19.2 \%$ respectively. $^{7}$

Elevated blood pressure has many potential risk factors which are related with a behavioral, dietary and genetic factors. The main modifiable risk factors of hypertension are being overweight or obese, cigarette smoking, physical inactivity, unhealthy diet, stress, and alcohol use. The regular intake of Khat has also been reported as a risk factor for hypertension. ${ }^{8}$

The prevalence of hypertension was significantly higher among regular Khat chewers $(13.4 \%)$ than nonchewers $(10.7 \%)$, odds ratio $(\mathrm{OR})=1.66(95 \%$ CI 1.05 , 3.13). A considerably higher proportion of chewers $(29.9 \%)$ than non-chewers $(20.6 \%)$ had sub-optimal diastolic blood pressure $>80 \mathrm{mmHg}{ }^{8}$

During Khat chewing, most of the alkaloids are extracted into saliva. Maximum plasma concentration is reached (tmax) after $2.3 \mathrm{hrs}$ for cathinone, $2.6 \mathrm{hrs}$ for cathine and $2.8 \mathrm{hrs}$ for norephedrine. The participants who chewed 36-59 grams of khat for 1- hour duration were shown to have increased systolic and diastolic blood pressures for $3 \mathrm{hrs}$ after chewing. This elevated blood pressure becomes chronic with long term use of Khat. ${ }^{9,10}$

The heart rate and blood pressure are increased secondary to the enhanced sympathetic activity of cathinone. Cathinone appears to be the main ingredient of Khat responsible for elevated blood pressure. Regular Khat chewing and the persistent presence of cathinone within plasma results in prolonged vasoconstriction and results in chronically elevated blood pressure. ${ }^{5,11-15}$ Elevated systolic blood pressure among frequent chewers was fourteen times more compared to less frequent chewers (AOR:14.95, 95\% CI:5.49-40.66). ${ }^{16}$

Among patients with acute coronary syndrome in Yemen, $72.2 \%$ were regular Khat chewers. People who chew Khat regularly have a significantly higher risk of death following stroke and heart failure. ${ }^{17}$ Chronic Khat chewing has also been associated with the increased incidence of acute coronary vasospasm and myocardial infarction. ${ }^{18}$

The duration of Khat chewing and the number of hours spent per session of chewing Khat appears to directly associated with hypertension. Those who spent more than $6 \mathrm{hrs}$ in Khat chewing session were almost 9 times more likely to have an elevated diastolic blood pressure compared with those who spent less than $6 \mathrm{hrs}$ (AOR:8.99, 95\% CI: $4.85-16.66) .{ }^{19,20}$

A nationwide survey in Ethiopia showed that $18.7 \%$ of youths chewed Khat regularly. In a study conducted in Butajira town, Ethiopia, $50 \%$ of adults aged 15 years or older were found to be regular Khat chewers. ${ }^{21}$ Despite its adverse health impact, the prevalence of Khat chewing seems to be increasing. ${ }^{22}$

Numerous studies have been undertaken to assess the acute effect of Khat consumption on blood pressure. Few studies have, however, assessed the association of chronic Khat chewing with hypertension. The current study was undertaken to assess the association of chronic Khat chewing with systolic and diastolic blood pressure among adults in the Gurage zone of southern Ethiopia. The study also assessed the association of sex, marital status, level of education, BMI, smoking, alcohol consumption and Khat chewing with the presence of hypertension in this region.

\section{Materials and Methods}

This study was undertaken in the Gurage zone which is one of the 14 zones of Southern Ethiopia. The administrative center of this zone is Wolkite. Based on the 2015 Central Statistical Agency of Ethiopia report, this zone had a total population of $3,567,377$ with an area of $5893.40 \mathrm{~km}^{2}$. In addition, this zone comprises thirteen districts. Khat is cultivated in all parts of this zone and is widely chewed by both urban and rural communities.

A community based comparative cross-sectional study was conducted from October 5, 2018 to February 15, 2019 to assess the association of chronic chat chewing with blood pressure and predictors of hypertension among adults. All adults aged 18-65 years who met the inclusion 
criteria participated in the study. For Khat chewers the inclusion criteria were adults who chewed Khat for at least four years and in non-chewers there was no history of Khat chewing in their lifetime nor a family or personal history of hypertension. Those who had drunk coffee or alcohol or smoked a cigarette within $4 \mathrm{hrs}$ before data collection plus pregnant women and those who had mental health issues and chronic diseases (renal disease and diabetes) were excluded from the study.

The sample size was calculated using the general formula for comparison of two means i.e. $\mathrm{n}=\left(\mathrm{S}_{1}{ }^{2}+\mathrm{S}_{2}{ }^{2}\right)\left(\mathrm{Z}_{\alpha / 2}+\mathrm{Z}_{\beta}\right)^{2} / \mathrm{d}^{2}$ where, n: sample size, $Z_{\alpha / 2}$ : $Z$-value corresponding to $95 \%$ confidence interval, $\mathrm{Z}_{\beta}$ : $\mathrm{Z}$-value corresponding to one-sided power of $95 \%, \mathrm{~S}_{1}$ : standard deviation among chewers, $\mathrm{S}_{2}$ : standard deviation among non-chewers and $\mathrm{d}$ : minimum detectable difference. ${ }^{22}$ The sample size was estimated by considering the mean (standard deviation) of diastolic blood pressure as 75.0 (11.6) $\mathrm{mmHg}$ among Khat chewers and 72.9 (11.7) $\mathrm{mmHg}$ among non-chewers reported in a previous study, ${ }^{8} 95 \%$ confidence interval (CI), 95\% power, minimum detectable difference of $2.1 \mathrm{mmHg}$ and design effect of 1.5 . Substituting the above values to the formula gave a sample of 800. Multiplying it by design effect of 1.5 gave a total sample of 1200 . This sample was equally divided into chewers and non-chewers so 600 Khat chewers and 600 non-chewers were included in the study.

Five districts from 13 districts in the Gurage zone were drawn randomly. The five districts selected by the lottery method were Cheha, Ezha, Meskane, Sodo, and Wolkite. The selected districts were then further divided into smaller geographic units within the administrative center (known as kebeles) and four kebeles were drawn from each district making a total of 20 kebeles selected randomly. The total sample size was allocated to the selected districts based on probability proportion. Accordingly, 62 participants from Wolkite, 242 participants from Cheha woreda, 294 participants from Ezha woreda, 318 participants from Meskane woreda and 284 participants from Sodo woreda were selected by convenience sampling methods. Both Khat chewers and non-chewers were selected using similar processes.

Eight health professionals were trained in the main areas of research and methods for data collection. The data were collected by these trained health professionals in collaboration with local health workers. The data were collected in the morning (7: 00 am-10:00 am) at time usually free from Khat chewing. All Khat chewers included in the study had to avoid chewing Khat for
$8 \mathrm{hrs}$ prior to data collection. This $8 \mathrm{hr}$ gap between chewing Khat and collecting data was aimed to eliminate the acute rise in blood pressure that occurs after chewing Khat. Socio-demographic and other related characteristics of the participants were collected as part of the interviewer-administered questionnaire. After collecting this information, blood pressure measurements were carried out. The blood pressure measurement was taken from the right arm supported at heart level after the participant had been sitting at rest for five minutes and was taken using a mercury BP apparatus. The mean values of three BP measurements were used for analysis. If there was $4 \mathrm{mmHg}$ or greater difference within 3 measurements the measurement was repeated once. The internal consistency of measurements across 8 health professionals was examined by Cronbach's alpha that shown high internal consistency. In addition, the body weight and height of the participants were measured by using standard beam balance and erect height measuring scale. The instruments were calibrated before each measurement.

The level of BP was based on the new ACC/AHA high blood pressure guidelines. ${ }^{23}$ Accordingly, BP was categorized as normal ( $\mathrm{BP}<120 / 80 \mathrm{mmHg}$ ), elevated (systolic blood pressure between $120-129 \mathrm{mmHg}$ and diastolic blood pressure $<80 \mathrm{mmHg}$ ), stage I (systolic blood pressure between $130-139$ or diastolic blood pressure between $80-89 \mathrm{mmHg}$ ) and stage 2 (systolic blood pressure at least $140 \mathrm{mmHg}$ or diastolic blood pressure at least $90 \mathrm{~mm} \mathrm{Hg}$ ). The body mass index (BMI) of the participants was classified as underweight $\left(\mathrm{BMI}<18.5 \mathrm{~kg} / \mathrm{m}^{2}\right.$ ), normal (BMI between $18.5-24.9 \mathrm{~kg} / \mathrm{m}^{2}$ ) and overweight $\left(\mathrm{BMI} \geq 25 \mathrm{~kg} / \mathrm{m}^{2}\right){ }^{24}$

To ensure data quality, a pretest was undertaken on 5\% of the sample size on people who did not participate in the study. Based on the pretest, necessary corrections such as adjusting the order of questions, adding necessary variables and removing unnecessary variables were performed. The completeness of data was checked daily. In addition, intensive training was given for all data collectors and double data entry was done to ensure quality.

The data were entered and analyzed using SPSS version 23. The results were described by using texts and tables. Descriptive statistics were used to summarize socio-demographic and other related characteristics of the participants. Bivariate and multiple linear regression and binary logistic regression analysis were performed to identify the determinant factors of blood pressure. The test of statistically significant association was declared by using 95\% CI and p-value less than 0.05 . 


\section{Results}

\section{Socio-Demographic Characteristics}

1198 adults participated in the study giving a response rate of $99.8 \%$. Of the total study participants, 647 (54.0\%) were males with 328 Khat chewers and 319 non-chewers. From the total sample, $876(73.1 \%)$ respondents had normal BMI values and 1024 (84.5\%) respondents were urban residents. The mean (SD) age of Khat chewers and non-chewers were $34.0( \pm 11.27)$ years and $34.73( \pm 11.48)$ years, respectively. Intake of dietary salt was low among all study participants. Both groups were comparable and there were no significant differences between the two groups in terms of sex, marital status, residence, level of education, body mass index and mean age $(\mathrm{p}>0.05)$ (Table 1$)$.

\section{Khat Chewing Status of the Chewers}

Three hundred fifty-three (58.9\%) of the chewers had a history of regular Khat chewing for 4-10 years. Three hundred fifty-four (59.1\%) Khat chewers started due to peer pressure. The remaining, 217 (36.2\%) and 28 (4.7\%) chewers reported that they started to chew Khat to stay awake or due to family pressure. Most of the chewers, 342 (57.1\%) chewed Khat daily and 360 (60.1\%) chewers spent $2-3 \mathrm{hrs}$ per each chewing session (Table 2).

\section{Alcohol Intake and Smoking Status}

Among the total study participants, 151 (12.6\%) respondents had a history of cigarette smoking. The majority of the smokers, 90 (59.6\%) smoked 3-5 cigarettes per day followed by $47(31.1 \%)$ who smoked 6-10 cigarettes per day and the remaining, $14(9.3 \%)$ smoked more than 10 cigarette per day. Most of the smokers, 139 (92.1\%) were also Khat chewers and smoking was significantly associated with Khat chewing $(\mathrm{p}<0.001)$. With regard to consuming alcohol, 537 (44.8\%) participants were consumers of alcohol. Among the participants with an alcohol history, 142 (26.4\%) consumed alcohol daily followed by 202 (37.6\%) who consumed alcohol three times per week and the remaining, 193 (36.9\%) consumed alcohol occasionally. Alcohol drinking was significantly associated with Khat chewing $(\mathrm{p}<0.001)$ (Table 3).

\section{Blood Pressure}

The mean systolic blood pressure was significantly higher among Khat chewers compared with non-chewers (122.22 $\pm 17.84 \mathrm{mmHg}$ versus $109.25 \pm 15.08 \mathrm{mmHg}$, mean difference $=12.96 \mathrm{mmHg}[95 \%$ CI 11.09, 14.83], $\mathrm{p}<0.001)$. Similarly,
Table I Socio- Demographic Characteristics of the Study Participants in Gurage Zone, Southern Ethiopia, 2019

\begin{tabular}{|c|c|c|c|}
\hline Variables & $\begin{array}{l}\text { Non Chewer } \\
(n=599)\end{array}$ & $\begin{array}{l}\text { Chewer } \\
(n=599)\end{array}$ & p-value \\
\hline $\begin{array}{c}\text { Residence } \\
\text { Urban } \\
\text { Rural }\end{array}$ & $\begin{array}{l}505 \text { (84.3\%) } \\
94 \text { (I5.7\%) }\end{array}$ & $\begin{array}{l}519(86.6 \%) \\
80(13.4 \%)\end{array}$ & 0.251 \\
\hline $\begin{array}{l}\text { Sex } \\
\qquad \text { Male } \\
\text { Female }\end{array}$ & $\begin{array}{l}319(53.3 \%) \\
280(46.7 \%)\end{array}$ & $\begin{array}{l}328(54.8 \%) \\
27 \mid(45.2 \%)\end{array}$ & 0.602 \\
\hline *Age (years) & 34.0 (II.27) & 34.73 (II.48) & 0.335 \\
\hline $\begin{array}{l}\text { Marital status } \\
\text { Married } \\
\text { Single } \\
\text { Widow/widower } \\
\text { Divorced }\end{array}$ & $\begin{array}{l}289(48.2 \%) \\
290(48.4 \%) \\
13(2.2 \%) \\
7(1.2 \%)\end{array}$ & $\begin{array}{l}31 \mid(51.9 \%) \\
258(43.1 \%) \\
14(2.3 \%) \\
16(2.7 \%)\end{array}$ & 0.101 \\
\hline $\begin{array}{l}\text { Religion } \\
\text { Orthodox } \\
\text { Muslim } \\
\text { Protestant } \\
\text { Others }\end{array}$ & $\begin{array}{l}323(53.9 \%) \\
172(28.7 \%) \\
73(\mid 2.2 \%) \\
31(5.2 \%)\end{array}$ & $\begin{array}{l}312(52.1 \%) \\
244(40.7 \%) \\
29(4.8 \%) \\
14(2.4 \%)\end{array}$ & $<0.001$ \\
\hline $\begin{array}{c}\text { Ethnicity } \\
\text { Gurage } \\
\text { Amhara } \\
\text { Kebena } \\
\text { Oromo } \\
\text { Other }\end{array}$ & $\begin{array}{l}418(69.8 \%) \\
95(15.8 \%) \\
16(2.8 \%) \\
47(7.8 \%) \\
23(3.8 \%)\end{array}$ & $\begin{array}{l}469(78.3 \%) \\
28(4.7 \%) \\
31(5.2 \%) \\
23(3.8 \%) \\
48(8.0 \%)\end{array}$ & $<0.001$ \\
\hline $\begin{array}{l}\text { Level of education } \\
\text { Illiterate } \\
\text { Primary school } \\
\text { Secondary school } \\
\text { Diploma and above }\end{array}$ & $\begin{array}{l}74(12.5 \%) \\
134(22.4 \%) \\
164(27.4 \%) \\
227(37.9 \%)\end{array}$ & $\begin{array}{l}67(11.2 \%) \\
161(26.9 \%) \\
167(27.9 \%) \\
204(33.6 \%)\end{array}$ & 0.115 \\
\hline $\begin{array}{l}\text { Occupation } \\
\text { Merchant } \\
\text { Government employed } \\
\text { Self employed } \\
\text { Unemployed } \\
\text { Daily labors } \\
\text { Others }\end{array}$ & $\begin{array}{l}130(21.7 \%) \\
166(27.7 \%) \\
108(18.0 \%) \\
42(7.0 \%) \\
25(4.2 \%) \\
128(21.4 \%)\end{array}$ & $\begin{array}{l}\mid 27(2 \mid .2 \%) \\
\mid 46(24.4 \%) \\
|4|(23.5 \%) \\
57(9.5 \%) \\
79(\mid 3.2 \%) \\
53(\mid 0.7 \%)\end{array}$ & $<0.001$ \\
\hline $\begin{array}{l}\text { BMI }\left(\mathbf{k g} / \mathbf{m}^{2}\right) \\
\quad<18.5 \\
18.5-24.9 \\
\geq 25\end{array}$ & $\begin{array}{l}77 \text { (I2.9\%) } \\
44 I(73.6 \%) \\
8 I(\mid 3.5 \%)\end{array}$ & $\begin{array}{l}61(10.2 \%) \\
435(72.6 \%) \\
103(17.2 \%)\end{array}$ & 0.104 \\
\hline
\end{tabular}

Note: *Data are expressed in mean (standard deviation).

Abbreviation: BMI, Body Mass Index.

the mean diastolic blood pressure was significantly higher among Khat chewers compared with non-chewers (75.71 \pm $12.21 \mathrm{mmHg}$ versus $68.08 \pm 11.31 \mathrm{mmHg}$, mean difference $=$ $7.64 \mathrm{mmHg}$ [95\% CI 6.30, 8.97], $\mathrm{p}<0.001)$. The prevalence 
Table 2 Pattern of Khat Chewing Among Khat Chewers in Gurage Zone, Southern Ethiopia, 2019 ( $n=599)$

\begin{tabular}{|l|l|l|}
\hline Variables & Categories & n (\%) \\
\hline Chewing duration (years) & $4-10$ & $353(58.9)$ \\
& $11-15$ & $133(22.2)$ \\
& $>15$ & $113(18.9)$ \\
\hline Chewing frequency & Daily & $342(57.1)$ \\
& Ones per week & $14(2.3)$ \\
& Twice per week & $87(14.5)$ \\
& More than 3 times per week & $132(22.0)$ \\
& Less than once per week & $24(4.1)$ \\
\hline Time spent per each session & $\leq 1$ hr per day & $112(18.7)$ \\
& 2-3 hrs per day & $360(60.1)$ \\
& $4-5$ hrs per day & $94(15.7)$ \\
& $>5$ hrs per day & $33(5.5)$ \\
\hline Cost per day in ETB & I-50 ETB & $358(59.8)$ \\
& 5 I-I00 ETB & $197(32.9)$ \\
& $>100$ ETB & $44(7.3)$ \\
\hline
\end{tabular}

Abbreviation: ETB, Ethiopian birr.

Table 3 Cross Tabulation of Alcohol Drinking and Smoking Status Among Khat Chewers and Non Chewers in Gurage Zone, Southern Ethiopia, 2019

\begin{tabular}{|l|l|l|l|l|}
\hline \multicolumn{2}{|l|}{ Variables } & \multicolumn{2}{l|}{ Khat Chewing } & \multirow{2}{*}{ P-value } \\
\cline { 3 - 4 } \multicolumn{2}{l|}{} & No, n (\%) & Yes, n (\%) & \\
\hline \multirow{2}{*}{ Smoking } & $\begin{array}{l}\text { No } \\
\text { Yes }\end{array}$ & $\begin{array}{l}587(56.1) \\
12(7.9)\end{array}$ & $\begin{array}{l}460(43.9) \\
139(92.1)\end{array}$ & $<0.001$ \\
\hline Alcohol use & $\begin{array}{l}\text { No } \\
\text { Yes }\end{array}$ & $\begin{array}{l}409(61.9) \\
190(35.4)\end{array}$ & $\begin{array}{l}252(38.1) \\
347(64.6)\end{array}$ & $<0.001$ \\
\hline
\end{tabular}

of diastolic blood pressure greater than $80 \mathrm{mmHg}$ was significantly higher among Khat chewers than in non-chewers (17.4\% versus $8.7 \%, \mathrm{p}<0.001$ ). Based on the new ACC/ AHA high blood pressure guidelines, the prevalence of hypertension was $55.8 \%$ among Khat chewers and $22.7 \%$ among non-chewers (Table 4).

\section{Association of Chronic Khat Chewing and other predictors with Blood Pressure}

In simple linear regression analysis, sex, age, BMI, alcohol intake, duration of smoking cigarettes and Khat chewing duration were significantly associated with both systolic and diastolic blood pressure. These variables with significant association on bivariate analysis were further analyzed using multiple linear regression models to identify independent predictors of systolic and diastolic blood pressure.
Table 4 Systolic and Diastolic Blood Pressure Values Among the Study Participants in Gurage Zone, Southern Ethiopia, 2019

\begin{tabular}{|c|c|c|c|}
\hline Variables & $\begin{array}{l}\text { Chewer } \\
(n=599)\end{array}$ & $\begin{array}{l}\text { Non Chewer } \\
(n=599)\end{array}$ & P-value \\
\hline $\begin{array}{l}\text { SBP }(\mathbf{m m H g}) \\
\quad<120 \\
120-129 \\
130-139 \\
\geq 140\end{array}$ & $\begin{array}{l}357(59.6 \%) \\
3(0.5 \%) \\
131(21.9 \%) \\
108(18.0 \%)\end{array}$ & $\begin{array}{l}518(86.5 \%) \\
0(0) \\
54(9.0 \%) \\
27(4.5 \%)\end{array}$ & $<0.001$ \\
\hline $\begin{array}{l}\text { DBP (mmHg) } \\
\quad<80 \\
\quad \geq 80\end{array}$ & $\begin{array}{l}495(82.6 \%) \\
104(17.4 \%)\end{array}$ & $\begin{array}{l}547(91.3 \%) \\
52(8.7 \%)\end{array}$ & $<0.001$ \\
\hline $\begin{array}{c}\text { SBP/DBP } \\
\text { Normal } \\
\text { Elevated } \\
\text { Stage I } \\
\text { Stage II }\end{array}$ & $\begin{array}{l}170(28.4 \%) \\
95(15.9 \%) \\
84(14.0 \%) \\
250(41.7 \%)\end{array}$ & $\begin{array}{l}397(66.3 \%) \\
66(11.0 \%) \\
28(4.7 \%) \\
108(18.0 \%)\end{array}$ & $<0.001$ \\
\hline $\begin{array}{l}\text { Hypertension } \\
\text { Yes } \\
\text { No }\end{array}$ & $\begin{array}{l}334(55.8 \%) \\
265(44.2 \%)\end{array}$ & $\begin{array}{l}136(22.7 \%) \\
463(77.3 \%)\end{array}$ & $<0.001$ \\
\hline
\end{tabular}

Abbreviations: SBP, systolic blood pressure; DBP, diastolic blood pressure.

After adjusting for these variables; sex, BMI, alcohol amount and Khat chewing duration remained significantly associated with systolic and diastolic hypertension. Females had a significantly lower risk of hypertension with a beta coefficient of 2.86 in comparison with males (Tables 5 and 6).

Binary logistic regression analysis showed that there was a significant association between chronic Khat chewing and hypertension. Participants with a history of 4-10 years of Khat chewing had 2.83 times higher risk of developing hypertension than non-chewers. Other variables such as age, BMI, history of alcohol intake and smoking history were also significantly associated with hypertension (Table 7).

\section{Discussion}

Khat is readily available in Ethiopia and it is a highly a valued export commodity. The number of Khat chewers is increasing and its consumption has become popular in all parts of the Ethiopian population. ${ }^{25}$ As the consumption of Khat is continuing to increase in Ethiopia, more studies are needed to assess association and adverse effects of Khat consumption on blood pressure. This study aimed to investigate the association of chronic Khat chewing on systolic and diastolic blood pressure and predictors of hypertension. 
Table 5 Simple and Multiple Linear Regression Model Examining the Association Between Different Variables with Systolic Blood Pressure Among Adults in Gurage Zone, Southern Ethiopia, $2019(\mathrm{n}=1198)$

\begin{tabular}{|c|c|c|c|c|c|c|c|c|}
\hline \multirow[t]{2}{*}{ Variables } & \multicolumn{4}{|c|}{ Simple Linear Regression } & \multicolumn{4}{|c|}{ Multiple Linear Regression } \\
\hline & $\begin{array}{l}\text { Beta } \\
\text { Coefficient }\end{array}$ & SE & $\begin{array}{l}95 \% \mathrm{CI} \text { for Beta } \\
\text { Coefficient }\end{array}$ & p-value & $\begin{array}{l}\text { Beta } \\
\text { Coefficient }\end{array}$ & SE & $\begin{array}{l}95 \% \mathrm{Cl} \text { for Beta } \\
\text { Coefficient }\end{array}$ & p-value \\
\hline Sex & -3.72 & 1.02 & $-5.73,-1.7 I)$ & $<0.001$ & -2.91 & 0.92 & $(-4.7 I,-1.06)$ & 0.002 \\
\hline Age & 0.44 & 0.04 & $(0.36,0.53)$ & $<0.001$ & 0.19 & 0.04 & $(0.10,0.28)$ & $<0.001$ \\
\hline BMI & 0.55 & 0.15 & $(0.25,0.84)$ & $<0.001$ & 4.03 & 0.88 & $(2.30,5.75)$ & $<0.001$ \\
\hline Alcohol amount & 2.17 & 0.28 & $(1.60,2.73)$ & $<0.001$ & 1.14 & 0.27 & $(0.60,1.68)$ & $<0.001$ \\
\hline Smoking duration & 0.49 & 0.11 & $(0.27,0.7 I)$ & $<0.001$ & 0.00 & 0.11 & $(-0.21,0.21)$ & 0.999 \\
\hline Chewing duration & 1.02 & 0.59 & $(0.90,1.13)$ & $<0.001$ & 0.83 & 0.06 & $(0.70,0.96)$ & $<0.001$ \\
\hline
\end{tabular}

Note: Numerical data in bold indicates statistically significant $(P<0.05)$.

Abbreviations: BMI, body mass index; SE, standard error; $\mathrm{Cl}$, confidence interval.

Table 6 Simple and Multiple Linear Regression Model Examining the Association Between Different Variables with Diastolic Blood Pressure Among Adults in Gurage Zone, Southern Ethiopia, 2019 ( $\mathrm{n}=1198$ )

\begin{tabular}{|c|c|c|c|c|c|c|c|c|}
\hline \multirow[t]{2}{*}{ Variables } & \multicolumn{4}{|c|}{ Simple Linear Regression Model } & \multicolumn{4}{|c|}{ Multiple Linear Regression Model } \\
\hline & Beta Coefficient & SE & $\begin{array}{l}95 \% \mathrm{Cl} \text { for Beta } \\
\text { Coefficient }\end{array}$ & p-value & Beta Coefficient & SE & $\begin{array}{l}95 \% \mathrm{Cl} \text { for Beta } \\
\text { Coefficient }\end{array}$ & p-value \\
\hline Sex & -2.35 & 0.71 & $(-3.76,-0.95)$ & $<0.001$ & -1.96 & 0.67 & $(-3.28,-0.64)$ & 0.004 \\
\hline Age & 0.20 & 0.03 & $(0.14,0.26)$ & $<0.001$ & 0.05 & 0.03 & $(-0.01,0.11)$ & 0.105 \\
\hline BMI & 0.47 & 0.10 & $(0.27,0.68)$ & $<0.001$ & 0.45 & 0.09 & $(0.25,0.64)$ & $<0.001$ \\
\hline Alcohol amount & 1.24 & 0.20 & $(0.84,1.64)$ & $<0.001$ & 0.69 & 0.20 & $(0.29,1.09)$ & 0.001 \\
\hline Smoking duration & 0.18 & 0.79 & $(0.02,0.33)$ & 0.026 & -0.09 & 0.07 & $(-0.24,0.06)$ & 0.251 \\
\hline Chewing duration & 0.57 & 0.43 & $(0.49,0.65)$ & $<0.001$ & 0.50 & 0.05 & $(0.41,0.60)$ & $<0.001$ \\
\hline
\end{tabular}

Notes: Numerical data in bold indicates statistically significant $(p<0.05)$.

Abbreviations: BMI, body mass index; SE, standard error; $\mathrm{Cl}$, confidence interval.

This study demonstrated a significant association of blood pressure with chronic Khat chewing. The mean systolic and diastolic blood pressure of the chewers was significantly higher than non-chewers. In line with this result, another study showed that the mean diastolic blood pressure among Khat chewers was significantly higher than in non-chewers. ${ }^{8}$ In addition, we found that age, BMI, smoking, alcohol, and duration of Khat chewing had a significant association with hypertension. Other studies have also found that daily cigarette smoking and regular Khat chewing was associated with increased mean diastolic blood pressure..$^{20,26}$

The current study has also shown that Khat chewing was significantly associated with cigarette smoking. This result is in line with other studies that have shown that cigarette smoking was significantly associated with the chronic use of Khat. ${ }^{27-29}$ Alcohol intake was also significantly associated with hypertension. This finding is similar to another study which reported that there was an increased risk of hypertension in those who consumed large amounts of ethanol ( $\geq 210$ gram per week) compared with those who did not consume alcohol over the 6 years of follow-up. ${ }^{30}$ High intake of alcohol stimulates the release of endothelin 1 and 2 as well as angiotensin II which are known to be potent vasoconstrictors. ${ }^{31,32}$ The association of prolonged and large amounts of alcohol intake with hypertension may also be explained by the large number of calories in alcohol that can result in unwanted weight gain which in itself is a risk factor for hypertension.

This study also demonstrated that there was significant association between BMI with systolic and diastolic blood pressures. This finding was is consistent with another study which reported that there was a significant positive correlation among BMI, systolic and diastolic hypertension. Furthermore, it showed that overweight/obese subjects were more likely to have hypertension than those with normal BMI. ${ }^{33}$ 
Table 7 Factors Associated with Hypertension Among Adults in Gurage Zone, Southern Ethiopia, 2019 (n =1198)

\begin{tabular}{|c|c|c|c|c|}
\hline \multirow[t]{2}{*}{ Variables } & \multicolumn{2}{|c|}{ Hypertension } & \multirow[t]{2}{*}{ COR $(95 \% \mathrm{Cl})$} & \multirow[t]{2}{*}{ AOR $(95 \% \mathrm{Cl})$} \\
\hline & No, n (\%) & Yes, n (\%) & & \\
\hline \multicolumn{5}{|l|}{ Sex } \\
\hline Male & $375(58)$ & $272(42)$ & 1 & 1 \\
\hline Female & $353(64.1)$ & 198(35.9) & $0.77(0.61,0.97)$ & $0.79(0.61,1.04)$ \\
\hline \multicolumn{5}{|l|}{ Age (years) } \\
\hline $15-24$ & $130(69.1)$ & $58(30.9)$ & 1 & I \\
\hline $25-34$ & $344(67.5)$ & $176(32.5)$ & $1.18(0.82,1.69)$ & $\mathrm{I} .0 \mathrm{I}(0.67, \mathrm{I} .5 \mathrm{I})$ \\
\hline $35-44$ & $\mid 48(57.80)$ & $108(42.2)$ & $1.63(1.10,2.43)$ & I.38 $(0.86,2.20)$ \\
\hline$\geq 45$ & $116(47.54)$ & $128(52.46)$ & $1.30(0.8 \mathrm{I}, 2.07)$ & $2.42(1.49,3.93)$ \\
\hline \multicolumn{5}{|l|}{ BMI } \\
\hline Under weight & $101(73.20)$ & $37(26.80)$ & 1 & 1 \\
\hline Normal & $545(62.20)$ & $331(37.80)$ & $1.65(1.11,2.47)$ & $2.38(1.49,3.8 \mathrm{I})$ \\
\hline Over weight & $82(44.60)$ & $102(55.4)$ & $3.39(2.11,5.46)$ & $4.91(2.83,8.54)$ \\
\hline \multicolumn{5}{|l|}{ Alcohol } \\
\hline No & $465(70.3)$ & $196(29.6)$ & 1 & I \\
\hline Yes & $263(49.0)$ & $274(51.0)$ & $2.47(1.95,3.13)$ & $1.85(1.24,2.75)$ \\
\hline \multicolumn{5}{|l|}{ Smoking } \\
\hline No & $683(65.2)$ & $364(34.8)$ & 1 & 1 \\
\hline Yes & $45(29.8)$ & $106(70.2)$ & $4.42(3.04,6.40)$ & $2.65(1.75,4.02)$ \\
\hline \multicolumn{5}{|c|}{ Chewing duration } \\
\hline Non chewer & $463(77.0)$ & $138(23.0)$ & 1 & 1 \\
\hline $4-10$ years & $182(51.6)$ & $|7|(48.40)$ & $3.15(2.37,4.18)$ & $2.83(2.04,3.90)$ \\
\hline$\geq \mathrm{II}$ years & $59(45.0)$ & $72(55.0)$ & $4.09(2.76,6.06)$ & $3.95(2.75,5.67)$ \\
\hline
\end{tabular}

Note: I- reference group, numerical data in bold indicates statistically significant $(p<0.05)$.

Abbreviations: BMI, Body mass index; COR, crude odds ratio; AOR, adjusted odds ratio.

The current study demonstrated that there was no significant difference in BMI among chewers and nonchewers. This is not consistent with other studies that suggest that Khat chewing is associated with appetite suppression. ${ }^{34}$ Khat has behavioral, chemical and neurophysiological effects on appetite and metabolism that result in reduced body weight. ${ }^{34}$ The difference in our study may be due to the alcohol intake which was associated with chronic Khat chewing. The alcohol consumers could be replacing these calories from alcohol.

We found that the duration of Khat chewing and time spent at each chewing session were associated with elevated systolic blood pressure. A study conducted in northern Ethiopia revealed that those who spent more than $6 \mathrm{hrs}$ in a Khat session were 7.25 times more likely to have elevated systolic blood pressure compared to those who spent less than $6 \mathrm{hrs} .{ }^{18}$ This is probably due to Khat or its active alkaloid cathinone impacting on both heart rate and contractility, thus increasing cardiac output, which is a major determinant of mean systolic blood pressure. ${ }^{35}$

Increased systolic blood pressure was significantly associated with chronic Khat chewing in our study. This is in line with another study that showed chronic Khat chewing was significantly associated with elevated systolic blood pressure. ${ }^{18}$ However, another study showed a nonsignificant positive association between systolic blood pressure and Khat chewing. ${ }^{8}$ The difference in the findings may be due to differences in duration, amount and frequency of Khat chewing and differences in the study populations studied.

In the present study, the participants who chewed Khat for 4-10 years and greater than 15 years had 2.83 and 3.95 times more likely to develop hypertension as compared to non-chewer. This result indicated that blood pressure increases with increasing duration of khat chewing. ${ }^{8,20}$ The frequency of Khat chewing had also a significant positive association with blood 
pressure. In line with our finding, a further study revealed that elevated systolic blood pressure among male chewers who chewed frequently was fourteen times greater than those who chewed less frequently. ${ }^{18}$

The present study also demonstrated that there is a significant positive association between chronic Khat chewing and diastolic blood pressure. This finding supports earlier reports that have shown regular Khat chewing was associated with elevated diastolic blood pressure. ${ }^{8,11,12,18,36-39}$ Beyond the transient rise in blood pressure due to the acute effect of Khat, persistent vasoconstriction may develop secondary to the prolonged effect of cathinone. Hence, elevated diastolic blood pressure due to chronic Khat chewing may be explained by persistent and sustained peripheral vasoconstriction. $^{8,9}$

The duration, frequency and amount of Khat chewed had a direct association with blood pressure. This may be due to the continuous effect of cathine and cathinone on the heart and peripheral blood vessels. This is in line with a study that showed cathinone is detectable in blood up to $10 \mathrm{hrs}$ after ingestion. Frequent chewing of Khat for long periods will expose chewers to the much longer effects of cathine and cathinone. ${ }^{9}$

This study had some limitations. First, it is not known whether the association of chronic chewing with systolic and diastolic blood pressure is due to cathinone or other Khat constituents. Khat contains many different compounds and we did not identify the specific compounds in this study. Second, the study was based on self-reported Khat chewing duration which may be subjected to recall bias. Finally, we could not identify the level of physical activity, level of stress exposure, negative affect, lipid profile, asymptomatic cardiovascular or other systemic diseases that may affect the results of our study.

\section{Conclusions}

The current study has shown that long term Khat consumption is associated with increased systolic and diastolic blood pressure. A considerably higher proportion of Khat chewers than non-chewers developed hypertension. Other socio-demographic factors such as sex, BMI, and alcohol intake were significantly associated with hypertension. To assess the cause and effect relationship between chronic Khat chewing and hypertension further studies with better defined cohorts and more basic science studies need to be undertaken.

\section{Abbreviations}

BP, Blood pressure; SBP, systolic blood pressure; DBP, diastolic blood pressure; BMI, body mass index; SD, standard deviation; COR, crude odds ratio; AOR, Adjusted odds ratio; CI, confidence interval; SE, standard error.

\section{Consent for Publication}

Not applicable.

\section{Ethics Approval and Informed Consent}

The study was reviewed, ethically approved and written ethical clearance was obtained from the Institutional Review Board (IRB) of Wolkite University with ethical approval reference number IRB/56/8/2010. Then, the letter of permission to conduct the study was obtained from the district's health office. The study participants were briefed about the study and written informed consent was obtained before the data collection. Confidentiality of the respondents' information was kept throughout the study.

\section{Data Sharing Statement}

The datasets used and/or analyzed during the current study are available from the corresponding author on reasonable request.

\section{Acknowledgments}

The authors would like to thank local health extension workers, all data collectors, staff members of the Gurage Zone Health Bureau, Wolkite, Cheha, Ezha, Meskane, and Sodo District Health Office for their cooperation during data collection. Our heartfelt gratitude goes to all study participants who agreed to participate in the study. We also thank Wolkite University for sponsoring this research project.

\section{Author Contributions}

TGG and GGW conceived and designed the study, supervised the data collection. Then all authors contributed to data analysis, drafting and revising the article, gave final approval of the version to be published, and agree to be accountable for all aspects of the work. 


\section{Funding}

This study was funded by Wolkite University. The funders had no role in study design, data collection, and analysis, decision to publish, or preparation of the manuscript.

\section{Disclosure}

The authors declare that they have no competing interests.

\section{References}

1. Megerssa B, Esayas A, Mohamed A. Socio-economic impact of Khat in Mana District, Jimma Zone, South Western Ethiopia. Agric Sci Eng Technol Res. 2013;4(1):44-59.

2. Al-Habori M. The potential adverse effects of habitual use of Catha edulis (Khat). Expert Opin Drg Saf. 2005;4(6):1145-1154. doi:10.1517/14740338.4.6.1145

3. Gelaw Y, Amlak AH. Khat chewing and its socio demographic correlates among the staff of Jimma University. Ethiop $J$ Health Dev. 2004;18(3):179-184.

4. Prasanthi G, Baburao C, Pradeep Kumar Y, Swarnalatha D, Gopinath C: Chemical pharmacology of khat leaves. JGTPS. 2014;5 (4):2024-2029.

5. Hassan NA, Gunaid AA, Abdo-Rabbo AA, Abdel-Kader ZY, AlMansoob MA, Awad AY. The effect of khat chewing on blood pressure and heart rate in healthy volunteers. Trop Doct. 2000;30 (2):107-108. doi:10.1177/004947550003000219

6. Patricia K, Megan W, Kristi R, Paul M, Paul K, Jiang H. Global burden of hypertension: analysis of worldwide data. Lancet. 2005;365:217-223. doi:10.1016/S0140-6736(05)17741-1

7. Kibret KT, Mesfin YM. Prevalence of hypertension in Ethiopia: a systematic meta-analysis. Public Health Rev. 2015;36:14. doi:10.1186/s40985-015-0014-z

8. Getahun W, Gedif T, Tesfaye F. Regular Khat (Catha edulis) chewing is associated with elevated diastolic blood pressure among adults in Butajira, Ethiopia: a comparative study. BMC Public Health 2010;10:390. doi:10.1186/1471-2458-10-390

9. Stefan W, Toennes SH, Schramm M, Niess C, Kauert GF. Pharmacokinetics of cathinone, cathine and norephedrine after the chewing of khat leaves. J Clin Pharmacol. 2003;56:125-130. doi:10.1046/j.1365-2125.2003.01834.x

10. Dhaifala I, Santavy J. Khat habit and its health effect. Natural amphetamine. Biomed Pap Med Fac Univ Palacky Olomouc Czech Repub. 2004;148(1):11-15. doi:10.5507/bp.2004.002

11. Al Motarreb KB. Coronary and aortic vasoconstriction by cathinone, the active constituent of khat. Auton Autacoid Pharmacol. 2003;23:319-326. doi:10.1111/j.1474-8673.2004.00303.x

12. Baker KE, Herbert AA, Broadley KJ. Vasoconstriction of porcine left anterior descending coronary artery by ecstasy and cathinone is not an indirect sympathomimetic effect. Vascul Pharmacol. 2007;47 (1):10-17. doi:10.1016/j.vph.2007.03.001

13. Kohli J, Goldberg J. Cardiovascular effects of cathinone in the anaesthetized dog: comparison with amphetamine. J Pharm Pharmacol. 1982;34 (5):338-340. doi:10.1111/j.2042-7158.1982.tb04722.x

14. Hassan NA, Gunaid AA, Abdo Rabbo AA, Abdel-Kader ZY, AlAwad AY, Murray-Lyon IM. The effect of khat chewing on blood pressure and heart rate in healthy volunteers. Trop Doc. 2000;30:107-108. doi:10.1177/004947550003000219

15. Sallam MA, Sheikh KA, Baxendale R, Azam MN, El-Setouhy M. The physiological and perceptual effects of plant extracts (Catha Edulis Forsk) during sustained exercise. Subst Abuse Treat Prev Policy. 2016;11:18. doi:10.1186/s13011-016-0063-4

16. Kalix P. Khat: A plant with amphetamine effects. $J$ Subst Abuse Treat. 1988;5(3):163-169. doi:10.1016/0740-5472(88)90005-0
17. Ali WM, Zubaid M, Al-Motarreb A, Singh R, Al-Shereiqi SZ. Association of khat chewing with increased risk of stroke and death with ACS. Mayo Clin Proc. 2010;85(11):974-980. doi:10.4065/ mcp. 2010.0398

18. Al-Motarreb A, Baker K, Broadley KJ. Khat: pharmacological and medical aspects and its social use in Yemen. Phytotherapy Res. 2002;16:403-413. doi:10.1002/(ISSN)1099-1573

19. Birhane BW, Birhane MW, Lebeta KR. Effects of khat chewing behaviours on health outcomes among male khat chewers in Bahir Dar, North West Ethiopia. Am J Biomed Life Sci. 2014;2(4):89-97. doi: $10.11648 /$ j.ajbls.20140204.15

20. Al-Motarreb A, Briancon S, Al-Jaber N, et al. Khat chewing is a risk factor for acute myocardial infarction: a case-control study. Br J Clin Pharmacol. 2004;59(5):574-581. doi:10.1111/j.1365-2125.2005.02358.x

21. Tesfaye F, Byass P, Berhane Y, Bonita R. S W. Association of smoking and khat (Catha edulis Forsk) use with high blood pressure among adults in Addis Ababa, Ethiopia. Prev Chronic Dis. 2008;5:3.

22. Sinshaw A, Messele A, Kssa H. Prevalence and associated factors of khat chewing among Atse Fasil Campus Students, University of Gondar, North West Ethiopia. J Psychol Clin Psychiatry. 2014;1:6. doi:10.15406/jpcpy.2014.01.00040

23. Charan J, Biswas T. How to calculate sample size for different study designs in medical research? Indian J Psychol Med. 2013;35 (2):121-126. doi:10.4103/0253-7176.116232

24. Wheliton P, Block P, Eagle K. New ACC/AHA high blood pressure guidelines lower definition of hypertension. Am Coll Cardiol. 2017.

25. WHO Expert Committee on Physical Status. Physical status: the use and interpretation of anthropometry. WHO Technical Report series no. 854, August 1, 1995. Geneva: World Health Organization.

26. Selassie SG, Gebre A. Rapid assessment of drug abuse in Ethiopia. Bull Narc. 1996;48:53-63.

27. Kassim S, Jawad M, Croucher R, Elie A. The epidemiology of tobacco use among khat users: a systematic review. Bio Med Res Int . 2015;2015:313692.doi:10.1155/2015/313692

28. Nakajima M, Molla K, Belachew B, et al. Khat use is associated with tobacco, alcohol, and illicit drug use: a cross-sectional examination in the United States. J Psychoactive Drugs. 2017;49(5):413-419. doi:10.1080/ 02791072.1342155 .

29. Hoffman R, al'Absi M. Concurrent use of khat and tobacco is Associated with Verbal Learning and delayed recall deficits. PMC. 2014;108(10):1855-1862.

30. Seifu W, Hussein M, Ibrahim M, Sigale A. Behavioral risk factors of hypertension among pastoral and agro pastoral adult communities, Eastern Ethiopia, Somali Regional State. J Trop Dis. 2017;5(2):234. doi:10.4172/2329-891X.1000234

31. Fuchs F, Chambless WP, Nieto F, Heiss G. Alcohol consumption and the incidence of hypertension: the atherosclerosis risk in communities study. Hypertension. 2001;37(5):1242-1250. doi:10.1161/01.HYP.37.5.1242

32. Lemieux AM, Li B, Al'Absi M. Khat use and appetite: an overview and comparison of amphetamine, khat and cathinone. J Ethnopharmacol. 2015;160:78-85. doi:10.1016/j.jep.2014.11.002

33. Tsuji S, Kawano S, Michida T, et al. Ethanol stimulates immunoreactive endothelin- 1 and -2 release from cultured human umbilical vein endothelial cells. Alcohol Clin Exp Res. 1992;16:347-349. doi:10.1111/acer.1992.16.issue-2

34. Wright JW, Morseth SL, Abhold RH, Harding JW. Elevations in plasma angiotensin II with prolonged ethanol treatment in rats. Pharmacol Biochem Behav. 1986;24:813-818. doi:10.1016/00913057(86)90416-8

35. Mungreiphy NK, Satwanti K, Rashmi S. Association between BMI, blood pressure, and age: study among Tangkhul Naga tribal males of Northeast India. J Anthropol. 2011. doi:10.1155/2011/748147

36. Chong ZX, Alshagga M, Saed KA, Kassim S. Impact of khat (catha edulis) chewing/use on heart rate and blood pressure: a critical review. Malaysian J Public Health Med. 2017;17(3):76-85. 
37. Al-Motarreb A, Al-Habori M, Broadley KJ. Khat chewing, cardiovascular diseases and other internal medical problems: thecurrent situation and directions for future research. $J$ Ethnopharmacol. 2010;132(3):540-548. doi:10.1016/j.jep.2010.07.001

38. Brenneisen R, Fisch HU, Koelbing U, Geisshusler SP, Kalix B. Amphetamine-like effects in humans of the khat alkaloid cathinone. $J$ Clin Pharmac. 1990;30:825-828. doi:10.1111/j.1365-2125.1990. tb05447.x
39. Benetos A, Zureik M, Morcet J. Decrease in diastolic blood pressure combined with an increase in systolic blood pressure is associated with a higher cardiovascular mortality in men. $J$ Am Coll Cardiol. 2000;35(3):673-680. doi:10.1016/S0735-1097(99)00586-0

\section{Publish your work in this journal}

Integrated Blood Pressure Control is an international, peer-reviewed open-access journal focusing on the integrated approach to managing hypertension and risk reduction. Treating the patient and comorbidities together with diet and lifestyle modification and optimizing healthcare resources through a multidisciplinary team approach constitute key features of the journal. This journal is indexed on

Submit your manuscript here: https://www.dovepress.com/integrated-blood-pressure-control-journal
American Chemical Society's Chemical Abstracts Service (CAS). The manuscript management system is completely online and includes a very quick and fair peer-review system, which is all easy to use. Visit http://www.dovepress.com/testimonials.php to read real quotes from published authors. 